\title{
Self-reported frequency and impact of hypoglycaemic events in insulin-treated diabetic patients in Austria
}

\author{
Raimund Weitgasser · Sandra Lopes
}

Received: 1 May 2014 / Accepted: 28 September 2014 / Published online: 25 November 2014

(C) The Author(s) 2014. This article is published with open access at Springerlink.com

\begin{abstract}
Background Hypoglycaemia is a common side effect of insulin therapy and presents a barrier to diabetes management, however, limited data exist on the real-world frequency of events. We investigated the self-reported rates of non-severe and severe hypoglycaemic events in Austria. We also explored hypoglycaemia awareness, patient-physician communication and the healthrelated and economic impact of events.

Methods People with Type-1 or insulin-treated Type-2 diabetes $>15$ years of age completed up to 4 questionnaires (weekly intervals). Non-severe hypoglycaemic events were defined by requiring no assistance while severe hypoglycaemic events need help from a third party.

Results Overall, 553 respondents (40\% Type-1, $60 \%$ Type-2) enrolled, providing a total of 1,773 patientweeks. The mean annual non-severe event frequencies were 85 for Type-1 and 15-28 for Type-2 (depending on insulin regimen). In respondents who experienced $\geq 1$ non-severe event in the study period, annual rates were $18 \%$ higher in Type- 1 and $77 \%$ higher in Type- 2 . The proportion of respondents reporting 'awareness' of hypoglycaemic symptoms was $48 \%$ for Type- 1 and $43-61 \%$ for Type- 2 respondents. The proportion of respondents who
\end{abstract}

\footnotetext{
S. Lopes $(\square)$

Novo Nordisk Scandinavia AB, Region Danmark,

Arne Jacobsens Allé 17, 9. sal,

2300 Copenhagen, Denmark

e-mail:SNLB@novonordisk.com

Assoc. Prof. Dr. R. Weitgasser Salzburg, Austria

Assoc. Prof. Dr. R. Weitgasser

Paracelsus Medical University Salzburg,

Salzburg, Austria
}

Department of Internal Medicine, Diakonissen Hospital Salzburg, rarely/never inform their physician of hypoglycaemic events was $67 \%$ (Type-1) and 43-53\% (Type-2). The most commonly reported health-related impacts were tiredness/fatigue ( $58 \%$ of events) and reduced alertness ( $41 \%$ of events).

Conclusion Non-severe hypoglycaemic events are common in Type-1 and insulin-treated Type-2 diabetes patients in Austria. There may be subgroups of patients who are predisposed to higher rates of non-severe events. Even non-severe events have a negative impact on physical and emotional well-being.

Keywords Diabetes mellitus · Hypoglycaemia · Insulin • Quality of life

Häufigkeit und Auswirkung von Hypoglykämien bei insulinbehandelten Diabetes-Patienten in Österreich

\section{Zusammenfassung}

Grundlagen Hypoglykämien sind ein häufiger Nebeneffekt der Insulintherapie und stellen eine Limitation im Diabetesmanagement dar, dennoch gibt es nur wenig Daten zu solchen Ereignissen im Alltag. Wir haben deshalb die Häufigkeit von selbst beobachteten nichtschweren und schweren Hypoglykämien in Österreich untersucht. Ebenfalls untersucht wurden Hyoglykämiewahrnehmung, Patient-Arzt Kommunikation und gesundheitliche sowie ökonomische Auswirkungen von Hypoglykämien.

Methodik Personen mit Typ 1 oder insulin-behandeltem Typ 2 Diabetes (>15 Lj.) füllten in wöchentlichen Abständen bis zu 4 Fragebögen aus. Nicht-schwere Hypoglykämien (NSHE) wurden als solche ohne, schwere als solche mit von außen benötigter Hilfe definiert.

Ergebnisse Der Fragebogenrücklauf belief sich auf 533 Personen (40\% Typ 1, 60\% Typ 2), insgesamt 1.773 
Patientenwochen entsprechend. Die durchschnittliche jährliche NSHE-Häufigkeit betrug 85 bei Typ 1 und 15-28 (abhängig von der Art des Insulinregimes) bei Typ 2. Bei Patienten, die $\geq 1$ NSHE während der Studiendauer hatten, war die jährliche Hypoglykämierate bei Typ 1 um $18 \%$, bei Typ 2 um $77 \%$ erhöht. Der Anteil der Patienten mit „Wahrnehmung“ hypoglykämischer Symptome lag bei $48 \%$ für Typ 1 und 43-61 \% für Typ 2. Der Anteil der Patienten, die selten/nie ihren Arzt über Hypoglykämien informieren, war $67 \%$ bei Typ 1 und 43-53\% bei Typ 2 .

Die am häufigsten berichteten gesundheitsbezogenen Auswirkungen waren Müdigkeit/Erschöpfung (58\% der NSHE) und eingeschränkte Aufmerksamkeit (41\% der NSHE).

Schlussfolgerung NSHE sind bei Typ 1 und insulinbehandelten Typ 2 Diabetespatienten in Österreich häufig. Subgruppen von Patienten mit einer Prädisposition für höhere Raten von NSHE könnten definiert werden. Selbst NSHE haben einen negativen Effekt auf das körperliche und emotionale Wohlbefinden.

Schlüsselwörter Diabetes mellitus · Hypoglykämie · Insulin · Lebensqualität

\section{Introduction}

According to the International Diabetes Federation (IDF) more than 56 million adults in Europe have been diagnosed with diabetes mellitus (2013 estimate), corresponding to a prevalence of $6.8 \%$ [1]. The prevalence in Austria is slightly higher, at 8-9\% [2].

A fundamental goal in the management of patients with diabetes is the maintenance of normoglycaemia, often through the use of insulin [3]. However, intensification of insulin therapy can increase the incidence of hypoglycaemia; the most common and unpredictable side effect of insulin treatment [4]. Hypoglycaemia can be defined as either non-severe or severe according to whether a patient can manage the event alone or requires third party assistance, respectively $[5,6]$. Nonsevere hypoglycaemic events (NSHEs), which account for $88-98 \%$ of all events $[7,8]$, are associated with a negative impact on health-related quality of life, healthcare resource use and work productivity $[7,9,10]$.

Hypoglycaemia presents a significant barrier to optimal diabetes management as fear of hypoglycaemic events may cause exaggerated avoidance behaviour and consequently sub-optimal insulin therapy and glycaemic control [11, 12]. Therefore, diabetes education has a critical role in diabetes management, and all diabetes patients in Austria are offered structured diabetes education, which aims to minimise the risk of diabetes-related complications and premature mortality. For Type 2 patients, a Disease Management Programme (DMP) for regular diabetes care by GPs was introduced in 2007 [13]. However, only $15-20 \%$ of Type 2 patients have enrolled in the programme, demonstrating an ongoing need for improved patient engagement in the management of their diabetes. Alongside patients, all physicians who care for people with diabetes are expected to attend the programme [13].

In Europe, data on the frequency of hypoglycaemia outside of clinical trial settings are limited and varied. The majority of literature focuses on Type 1 diabetes and the frequency of severe hypoglycaemic events (SHE). Four European studies have reported real-world estimates of NSHE rates $[4,8,10,14]$, however there are no data specific to the Austrian setting. The results of previous studies vary according to their definition of hypoglycaemic events, methods of data collection, and country coverage. Therefore there is a clear need to gain a better understanding of the patient perspective on the burden of hypoglycaemia, and their communication with healthcare professionals (HCPs) on the subject.

This paper reports the frequency of self-reported NSHEs and SHEs in people with Type 1 and insulintreated Type 2 diabetes mellitus (T1DM and T2DM) in Austria. Additionally, levels of impaired hypoglycaemia awareness, patient-physician communication of hypoglycaemic events and the health-related effects and economic impact of NSHEs are reported.

\section{Patients, materials and methods}

A full description of the methodology for this study has been previously described by Östenson et al., who investigated self-reported NSHE rates across seven Northern and Central European countries (Austria, Denmark, Finland, Norway, Sweden, Switzerland and the Netherlands) $[15,16]$.

The questionnaire-based survey was conducted in Austria between February and May 2012 People over the age of 15 with a T1DM or T2DM diagnosis receiving insulin were recruited using existing large online panels that provided a representative sample of the general diabetes population based on age, gender and other demographic characteristics. Respondents with T2DM were divided into three subgroups based on their insulin regimen: long acting-insulin only (basal only therapy; T2BOT), short and long acting insulin (basal-bolus; T2BB) or other insulin regimens (e.g. premix; T2O).

A small incentive was offered for completion of the questionnaire (approximately $€ 5-10$ in total), in line with current market research guidelines and to ensure there was no undue incentive to participate. Questionnaires were completed anonymously in accordance to the regulations and practice of market research governing bodies European Society for Opinion and Marketing Research (ESOMAR) [17] and European Pharmaceutical Market Research Association (EphMRA) [18].

Participants were invited to complete four questionnaires over four consecutive weeks. The first questionnaire collected information on respondent demographics, awareness of hypoglycaemic symptoms, communication of hypoglycaemic events with HCPs, frequency of NSHEs in the previous seven days, and the number of SHEs in the 
past year. The subsequent three questionnaires recorded only the frequency of NSHEs in the preceding seven days, and the impact of the most recent event. Data collected on the impact of hypoglycaemia included changes in respondent well-being, work productivity and healthcare resource use. Weekly NSHE frequencies were calculated using data from all participants completing at least one questionnaire (wave), with annual frequency calculated using the mean weekly event frequency multiplied by 52. NSHE frequencies are also presented for only those respondents who experienced a NSHE during the recall report.

The classification system for awareness of hypoglycaemia was based on a prospectively validated study by Pedersen-Bjergaard et al. [19]. Any respondent who answered 'sometimes' or 'never' to the question 'can you feel when your blood sugar is low?' was assigned as being unaware of hypoglycaemia, those who answered 'usually' as having impaired awareness and those who answered 'always' deemed to be aware.

Standard descriptive methods (means/percentage and standard deviations) were used to report results. Comparisons of NSHE frequencies according to respondent awareness and patient-physician communication were performed using t-tests with an employed significance level of $p<0.05$.

\section{Results}

Overall 553 respondents completed the first wave, with $82 \%, 72 \%$ and $67 \%$ completing waves 2,3 and 4 , respectively. This gives a total of 1,773 patient-week records in Austria. Patient demographics are shown in Table 1. In total, $40 \%$ of respondents had T1DM and $60 \%$ of respondents had T2DM.

The mean annual self-reported frequencies of NSHE were 85 for T1DM, 22 for T2DM, 15 for T2BOT, 28 for T2BB and 19 for T2O. Analysing results only from those respondents who experienced a NSHE during the recall period, annual NSHE rates were 100 in T1DM and 39 in T2DM (ranging from 33 in T2O to 43 in T2BB) (Table 2). The proportion of NSHEs which occurred at night-time was $19 \%$ for T1DM and $21 \%$ for T2DM respondents. After excluding respondents who did not experience any nocturnal NSHEs during the study period, the proportion of events occurring at night-time increased to $23 \%(n=29)$ in T1DM and $39 \%(n=20)$ in T2DM (Table 3).

Self-reported mean annual SHE frequencies were 0.7 for T1DM and 0.2 for T2DM ( 0.1 for T2BOT, 0.2 for T2BB and 0.2 for T2O).

The proportion of respondents who are reportedly 'aware' of hypoglycaemic symptoms was $48 \%$ in T1DM and $57 \%$ in T2DM respondents. Respondents who reported impaired awareness comprised $44 \%$ of T1DM respondents and $31 \%$ of T2DM respondents, with 7 and $12 \%$ being unaware, respectively (Table 4). For T1DM respondents, there was a trend for increased NSHE and SHE rates with decreasing awareness, however this was not significant (data not shown). NSHE rates for T2DM
Table 1 Respondent demographics

\begin{tabular}{|c|c|c|}
\hline & Type 1 & Type 2 \\
\hline Number of respondents, $\mathrm{N}(\%)$ & $222(40 \%)$ & $331(60 \%)$ \\
\hline Age, mean (SD) & $44.5(14.6)$ & $62.8(11.9)$ \\
\hline Gender, female, N (\%) & $113(51 \%)$ & $137(41 \%)$ \\
\hline \multicolumn{3}{|l|}{ Marital status, $N(\%)$} \\
\hline Single & $61(27 \%)$ & $78(24 \%)$ \\
\hline Married & $109(49 \%)$ & $211(64 \%)$ \\
\hline Partner & $52(23 \%)$ & $42(13 \%)$ \\
\hline \multicolumn{3}{|l|}{ Living arrangements, $N(\%)$} \\
\hline Alone & $34(15 \%)$ & $74(22 \%)$ \\
\hline With others & $188(85 \%)$ & $257(78 \%)$ \\
\hline Active employment, $N$ (\%) & $143(64 \%)$ & $74(22 \%)$ \\
\hline \multicolumn{3}{|l|}{ Education, $N(\%)$} \\
\hline Primary school & $67(30 \%)$ & $159(48 \%)$ \\
\hline High school & $101(46 \%)$ & $137(41 \%)$ \\
\hline University & $48(22 \%)$ & $28(8 \%)$ \\
\hline Other & $6(3 \%)$ & $7(2 \%)$ \\
\hline BMI, mean (SD) & $25.5(4.8)$ & $29.9(5.7)$ \\
\hline \multicolumn{3}{|l|}{ Diabetes duration, $N(\%)$} \\
\hline Mean years (SD) & $20.2(13.5)$ & $16.4(10.3)$ \\
\hline$<2$ years & $7(3 \%)$ & $3(1 \%)$ \\
\hline $2-5$ years & $21(10 \%)$ & $37(12 \%)$ \\
\hline $5-9$ years & $30(14 \%)$ & $44(14 \%)$ \\
\hline $10-14$ years & $30(14 \%)$ & $63(20 \%)$ \\
\hline $15+$ years & $126(59 \%)$ & $165(53 \%)$ \\
\hline \multicolumn{3}{|l|}{ Insulin treatment type, $N$ (\%) } \\
\hline Basal-only therapy & $13(6 \%)$ & $76(23 \%)$ \\
\hline Basal-bolus therapy & $135(61 \%)$ & $162(49 \%)$ \\
\hline Other insulin types & $74(33 \%)$ & $93(28 \%)$ \\
\hline \multicolumn{3}{|l|}{ Duration of insulin treatment, $N$ (\%) } \\
\hline Average in years (SD) & $18.5(13.5)$ & $8.3(6.7)$ \\
\hline$<2$ years & $13(6 \%)$ & $38(12 \%)$ \\
\hline $2-5$ years & $27(13 \%)$ & $91(29 \%)$ \\
\hline $5-9$ years & $25(12 \%)$ & $61(20 \%)$ \\
\hline $10+$ years & $149(70 \%)$ & $122(39 \%)$ \\
\hline \multicolumn{3}{|l|}{ Mean HbA1c } \\
\hline mean mmol/mol (SD) & $55.4(11.5)$ & $61.3(18.8)$ \\
\hline NGSP \%, (SD) & $7.2(1.1)$ & $7.8(1.7)$ \\
\hline Medical complications ${ }^{\mathrm{a}}$, none, $\mathrm{N}(\%)$ & $152(68 \%)$ & $125(38 \%)$ \\
\hline \multicolumn{3}{|c|}{$\begin{array}{l}\text { BMI Body mass index, HbA1c Haemoglobin A1c (glycosylated haemoglobin), } \\
\text { NGSP National Glycohaemoglobin Standardisation Programme, SD Standard } \\
\text { deviation } \\
\text { 'Questionnaire options for medical complications included: None, Eye } \\
\text { problems, Neuropathy, Cardiovascular disease, Renal disease, Amputations, } \\
\text { Other (please specify) }\end{array}$} \\
\hline
\end{tabular}

respondents were comparable regardless of the level of awareness (data not shown). There may also be an association between HbAlc levels and awareness, however, opposing trends are observed according to diabetes type. In T1DM respondents, low HbAlc corresponded with reduced unawareness $(6.7 \%$ in unaware versus $7.4 \%$ in 
Table 2 Self-reported, recalled rates of hypoglycaemic events (daytime and nocturnal combined)

\begin{tabular}{|c|c|c|c|c|c|}
\hline \multirow{2}{*}{$\begin{array}{l}\text { All respondents (1773 respondent-week records from } \\
553 \text { respondents) }\end{array}$} & \multirow{2}{*}{$\begin{array}{l}\text { T1DM }(n=222 \\
716 \mathrm{pw})\end{array}$} & \multicolumn{4}{|l|}{ T2DM } \\
\hline & & $\begin{array}{l}\text { T2DM }(n=331 \\
1,057 \mathrm{pw})\end{array}$ & $\begin{array}{l}\text { Т2В0Т }(n=76 ; \\
248 \mathrm{pw})\end{array}$ & $\begin{array}{l}\mathrm{T} 2 \mathrm{BB}(n=162 ; \\
532 \mathrm{pw})\end{array}$ & $\begin{array}{l}\text { T20 }(n=93 \\
277 \mathrm{pw})\end{array}$ \\
\hline Annual calculated NSHE rates (52 weeks), mean & 84.6 & 22.5 & 15.1 & 27.8 & 19.0 \\
\hline Patients who experienced $\geq 1$ NSHE in study period, $n(\%)$ & $177(80 \%)$ & $174(53 \%)$ & $28(37 \%)$ & $99(61 \%)$ & $47(51 \%)$ \\
\hline $\begin{array}{l}\text { Respondents who experienced } \geq 1 \text { NSHE in the study period } \\
\text { (daytime or nocturnal) }\end{array}$ & $\begin{array}{l}\text { T1DM }(n=177 \\
605 \mathrm{pw})\end{array}$ & $\begin{array}{l}\text { T2DM }(n=174 \\
605 \mathrm{pw})\end{array}$ & $\begin{array}{l}\text { Т2В0Т }(n=28 \\
103 \mathrm{pw})\end{array}$ & $\begin{array}{l}\text { T2BB }(n=99 ; \\
343 \mathrm{pw})\end{array}$ & $\begin{array}{l}\text { T20 }(n=47 \\
159 \mathrm{pw})\end{array}$ \\
\hline NSHEs/year, mean & 100.1 & 39.3 & 36.3 & 43.1 & 33.0 \\
\hline Nocturnal NSHEs/year, mean (\% of all NSHEs) & $19.1(19 \%)$ & $8.1(21 \%)$ & $8.1(22 \%)$ & $9.6(22 \%)$ & $4.9(15 \%)$ \\
\hline
\end{tabular}

Table 3 Self-reported, recalled rates of non-severe hypoglycaemic events (nocturnal only)

\begin{tabular}{|c|c|c|c|c|c|}
\hline \multirow{2}{*}{$\begin{array}{l}\text { All respondents (1773 respondent-week records from } \\
553 \text { respondents) }\end{array}$} & \multirow{2}{*}{$\begin{array}{l}\text { T1DM }(n=222 ; \\
716 \mathrm{pw})\end{array}$} & \multicolumn{4}{|l|}{ T2DM } \\
\hline & & $\begin{array}{l}\text { T2DM }(n=331 \\
1,057 \mathrm{pw})\end{array}$ & $\begin{array}{l}\text { Т2В0Т }(n=76 \\
248 \mathrm{pw})\end{array}$ & $\begin{array}{l}\text { T2BB }(n=162 \\
532 \mathrm{pw})\end{array}$ & $\begin{array}{l}\text { T20 (n=93; } \\
277 \mathrm{pw})\end{array}$ \\
\hline Nocturnal NSHEs/year, mean (\% of al NSHEs) & $16.1(19 \%)$ & $4.6(21 \%)$ & $3.4(22 \%)$ & $6.2(22 \%)$ & $2.8(15 \%)$ \\
\hline Patients who experienced $\geq 1$ nocturnal NSHE in study period, $n(\%)$ & $110(50 \%)$ & $72(22 \%)$ & $10(13 \%)$ & $48(30 \%)$ & $14(15 \%)$ \\
\hline $\begin{array}{l}\text { Respondents who experienced } \geq 1 \text { nocturnal NSHE in the study } \\
\text { period }\end{array}$ & $\begin{array}{l}\text { T1DM }(n=110 \\
392 \mathrm{pw})\end{array}$ & $\begin{array}{l}\text { T2DM }(n=72 \\
48 \mathrm{pw})\end{array}$ & $\begin{array}{l}\text { Т2В0Т }(n=10 \\
40 \mathrm{pw})\end{array}$ & $\begin{array}{l}\text { T2BB }(n=48 \\
162 \mathrm{pw})\end{array}$ & $\begin{array}{l}\text { T20 ( } n=14 ; \\
46 \mathrm{pw})\end{array}$ \\
\hline NSHEs/year, mean & 127.3 & 50.3 & 54.6 & 51.7 & 41.9 \\
\hline Nocturnal NSHE/year, mean & $29.4(23 \%)$ & $19.7(39 \%)$ & $20.8(38 \%)$ & $20.2(39 \%)$ & $17.0(41 \%)$ \\
\hline
\end{tabular}

Table 4 Self-reported respondent awareness of hypoglycaemia

\begin{tabular}{|c|c|c|c|c|c|c|}
\hline \multirow{2}{*}{\multicolumn{2}{|c|}{$\begin{array}{l}\text { All respondents who have previously } \\
\text { experienced a NSHE† }(n=396)\end{array}$}} & \multirow[t]{2}{*}{ T1DM $(n=189)$} & \multicolumn{4}{|l|}{ T2DM } \\
\hline & & & All T2DM $(n=207)$ & Т2В0Т $(n=35)$ & T2BB $(n=115)$ & $\mathrm{T} 20(n=57)$ \\
\hline \multirow{3}{*}{$\begin{array}{l}\text { Can you feel when } \\
\text { your blood sugar is } \\
\text { low? N (\%) }\end{array}$} & Always aware & $91(48 \%)$ & $119(57 \%)$ & $15(43 \%)$ & $69(60 \%)$ & $35(61 \%)$ \\
\hline & Impaired awareness & $84(44 \%)$ & $64(31 \%)$ & $10(29 \%)$ & $38(33 \%)$ & $16(28 \%)$ \\
\hline & Unaware & $14(7 \%)$ & $24(12 \%)$ & $10(29 \%)$ & $8(7 \%)$ & $6(11 \%)$ \\
\hline \multicolumn{7}{|c|}{$\begin{array}{l}\text { Hypoglycaemia 'awareness' relates to the respondents' self-reported ability to recognise the physical symptoms indicating the onset of a hypoglycaemic event } \\
\text { †Base: all respondents that have previously experienced a NSHE at any point (not just in study recall period) } \\
\text { NSHE Non-severe hypoglycaemic event, T1DM Type } 1 \text { diabetes mellitus, T2BB Type } 2 \text { diabetes mellitus respondents receiving basal bolus therapy/short and } \\
\text { long acting insulin, T2BOTType } 2 \text { diabetes mellitus respondents receiving basal only therapy/long acting insulin only, T2DM Type } 2 \text { diabetes mellitus, T2OType } \\
2 \text { diabetes mellitus respondents receiving other therapy (e.g. mixed insulin) }\end{array}$} \\
\hline
\end{tabular}

aware patients), however in T2DM higher HbAlc corresponded with reduced awareness $(8.4 \%$ in unaware versus $7.6 \%$ in aware patients).

Overall, $67 \%$ of T1DM and $49 \%$ of T2DM respondents rarely or never inform their general practitioner (GP)/ specialist about hypoglycaemic events. When respondents were asked about topics discussed during GP/ specialist consultations, $18 \%$ of T1DM and $20 \%$ of T2DM respondents reported that their GP/specialist did not ask about hypoglycaemia during routine appointments (Table 5). NSHE rates were similar regardless of the level of patient-physician communication (data not shown).
Respondents reported negative health-related impacts following their last NSHE, including feeling tired/fatigued (following 54 and $61 \%$ of NSHE in T1DM and T2DM, respectively), less alert (39 and $42 \%$ of NSHE in T1DM and T2DM) and ill/uncomfortable (19 and $22 \%$ of NSHE in T1DM and T2DM). Respondents' emotional wellbeing was also affected, with NSHE resulting in feeling emotionally low (following 32 and $35 \%$ of NSHE in T1DM and T2DM, respectively), anxious/nervous (26 and $40 \%$ in T1DM and T2DM) and moody (18 and $19 \%$ in T1DM and T2DM) (Fig. 1). The number of hours negative feelings lasted for was greater in T2DM respondents ( $7 \mathrm{~h}$ in T2DM versus $4 \mathrm{~h}$ in T1DM). Events which occurred 
Table 5 Patient-physician communication of hypoglycaemia

\begin{tabular}{|c|c|c|c|c|c|}
\hline \multirow{2}{*}{$\begin{array}{l}\text { All respondents who have previously experienced a NSHEa } \\
(n=396)\end{array}$} & \multirow[t]{2}{*}{ T1DM $(n=189)$} & \multicolumn{4}{|l|}{ T2DM } \\
\hline & & All T2DM $(n=207)$ & Т2B0T $(n=35)$ & T2BB $(n=115)$ & $\mathrm{T} 20(n=57)$ \\
\hline $\begin{array}{l}\text { Proportion of respondents who rarely/never inform their GP/ } \\
\text { specialist about NSHEs, } \mathrm{N}(\%)\end{array}$ & $126(67 \%)$ & $101(49 \%)$ & $15(43 \%)$ & $56(49 \%)$ & $30(53 \%)$ \\
\hline Based on all respondents completing wave $1(n=553)^{b}$ & $\operatorname{T1DM}(n=222)$ & All T2DM $(n=331)$ & Т2В0Т $(n=76)$ & T2BB $(n=162)$ & $\mathrm{T} 20(n=93)$ \\
\hline $\begin{array}{l}\text { GP/specialist did not ask about hypoglycaemia during routine } \\
\text { appointments }\end{array}$ & $18 \%$ & $20 \%$ & $14 \%$ & $25 \%$ & $16 \%$ \\
\hline \multicolumn{6}{|c|}{$\begin{array}{l}\text { NSHE Non-severe hypoglycaemic event, SD Standard deviation, T1DM Type } 1 \text { diabetes mellitus, T2BB Type } 2 \text { diabetes mellitus respondents receiving basal } \\
\text { bolus therapy/short and long acting insulin, T2BOTType } 2 \text { diabetes mellitus respondents receiving basal only therapy/long acting insulin only, T2DM Type } 2 \\
\text { diabetes mellitus, T2OType } 2 \text { diabetes mellitus respondents receiving other therapy (e.g. mixed insulin) } \\
\text { aBase: all respondents that have previously experienced a NSHE at any point (not just in study recall period) } \\
\text { 'Base: All respondents completing wave } 1 \text { ( } n=396)\end{array}$} \\
\hline
\end{tabular}

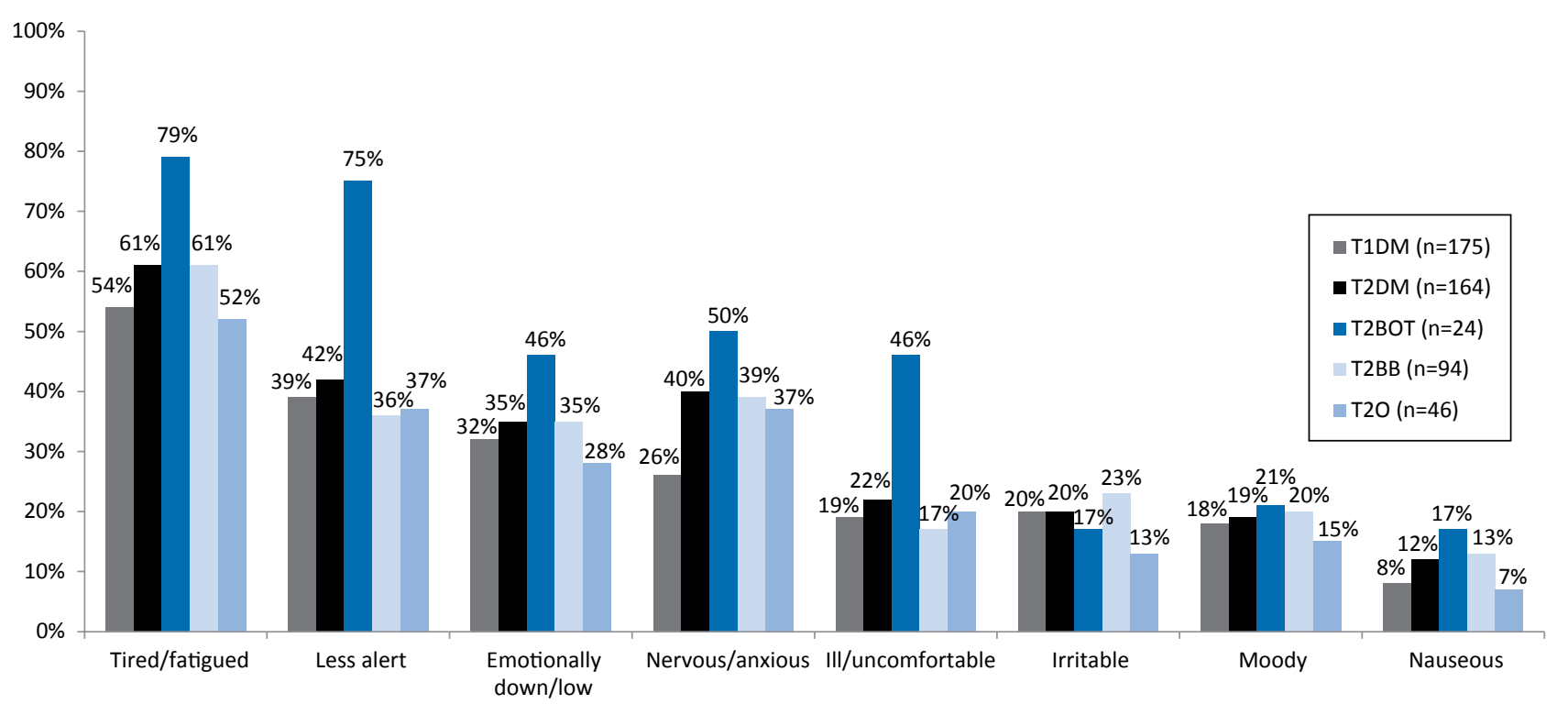

Fig. 1 Negative health-related impacts of NSHEs.

From left to right: most common response to least common response, based on combined results from Type 1 diabetes mellitus and Type 2 diabetes mellitus. NSHE Nonsevere hypoglycaemic event, T1DM Type 1 diabetes mellitus, T2BB Type 2 diabetes mellitus respondents receiving basal bolus therapy/short and long acting insulin, T2BOT Type 2 diabetes mellitus respondents receiving basal only therapy/long acting insulin only, T2DM Type 2 diabetes mellitus, T2O Type 2 diabetes mellitus respondents receiving other therapy (e.g. mixed insulin)

at night-time had a longer lasting impact than events during the day: 7 versus $4 \mathrm{~h}$ in T1DM and 8 versus $6 \mathrm{~h}$ in T2DM. NSHEs also impacted upon respondents' daily routine. The three most common impacts were reduced energy levels, daytime sleeping and difficulty concentrating. These overall findings were reflected in the specific results for respondents with T1DM or T2DM. T1DM respondents reported having less energy than usual following $34 \%$ (daytime) and $50 \%$ (nocturnal) of NSHE, with $25 \%$ (daytime) and $23 \%$ (nocturnal) NSHE resulting in daytime sleeping. T2DM respondents reported similar trends with $56 \%$ of daytime and $32 \%$ of nocturnal NSHE resulting in reduced energy levels and $56 \%$ (daytime) and $29 \%$ (nocturnal) of NSHE leading to daytime sleeping.

NSHEs reported during the study period resulted in increased use of healthcare resources (Table 6) [16]. Over the seven days following a NSHE, blood glucose test-strip use increased by a mean of $4.1(13 \%)$ in T1DM and 3.7 $(17 \%)$ in T2DM respondents. In T1DM and T2DM respondents combined, $6 \%$ of NSHE led respondents to contact a HCP (Table 6). A greater proportion of respondents with T2DM contacted a HCP, regardless of the time of day that the event occurred (daytime NSHE: $10 \%$, nocturnal NSHE $9 \%)$. In employed T1DM respondents ( $n=143), 8 \%$ of NSHE led to lost work time with approximately $3.0 \mathrm{~h}$ work time lost per event. In employed T2DM respondents $(n=74), 14 \%$ of NSHE led to lost work time, with approximately $4.3 \mathrm{~h}$ work time lost per event (Table 6).

\section{Discussion}

This study evaluates the real world frequency of NSHEs and SHEs in people with T1DM and insulin-treated 
Table 6 Direct and indirect economic impacts of hypoglycaemic events

\begin{tabular}{|c|c|c|}
\hline Last NSHE across all respondents & T1DM & T2DM \\
\hline \multicolumn{3}{|l|}{ NSHE resulting in contact with HCP } \\
\hline Overall, \% (n) & $3(12)$ & $10(33)$ \\
\hline Daytime NSHE, \% (n) & $3(11)$ & $10(27)$ \\
\hline Nocturnal NSHE, \% (n) & $1(1)$ & $9(6)$ \\
\hline $\begin{array}{l}\text { Self-reported number of BGM tests use in the aver- } \\
\text { age week, mean }\end{array}$ & 30.4 & 22.2 \\
\hline \multicolumn{3}{|l|}{ Mean increase in BGM use in the 7 days following a NSHE } \\
\hline Overall & 4.1 & 3.7 \\
\hline Daytime NSHE & 3.5 & 3.8 \\
\hline Nocturnal NSHE & 5.9 & 3.1 \\
\hline \multicolumn{3}{|l|}{ Last NSHE from employed respondents } \\
\hline \multicolumn{3}{|l|}{ NSHE leading to lost work time, $\%$} \\
\hline Overall, \% (n) & $8(23)$ & $14(12)$ \\
\hline Daytime NSHE, \% (n) & $8(21)$ & $13(8)$ \\
\hline Nocturnal NSHE, \% (n) & $4(2)$ & $18(4)$ \\
\hline \multicolumn{3}{|l|}{$\begin{array}{l}\text { Mean work time lost after a NSHE (in respondents who } \\
\text { lost work time), mins }\end{array}$} \\
\hline Overall & 181.9 & 256.5 \\
\hline Daytime NSHE & 185.0 & 131.3 \\
\hline Nocturnal NSHE & 150.0 & 507.0 \\
\hline $\begin{array}{l}\text { NSHE leading to self-reported inability to complete } \\
\text { a work task in a timely manner, \% }\end{array}$ & 42 & 38 \\
\hline $\begin{array}{l}\text { NSHE resulting in self-reported difficulty concen- } \\
\text { trating at work, \% }\end{array}$ & 27 & 28 \\
\hline \multicolumn{3}{|c|}{$\begin{array}{l}\text { BGM blood glucose measurement, } H C P \text { healthcare professional, Mins } \\
\text { Minutes, N/A Not applicable, NSHE Non-severe hypoglycaemic event, SHE } \\
\text { severe hypoglycaemic event, T1DM Type } 1 \text { diabetes mellitus, T2DM Type } 2 \\
\text { diabetes mellitus }\end{array}$} \\
\hline
\end{tabular}

T2DM in Austria. In addition, it provides insight into hypoglycaemic awareness, patient-physician communication and the health-related and economic impacts linked to non-severe events.

The frequency of NSHEs in T1DM respondents in Austria (1.6 per week), is slightly lower than in three previously conducted studies in Northern and Central Europe, which reported NSHE frequencies of 1.8, 2.0 and 2.2 per respondent, per week $[15,20,21]$. However, event rates in T2DM respondents ( 0.4 per week) are similar to those reported in a prospective single-centred study in Scotland (0.3 per week) [8]. The Austrian NSHE rate is generally similar to the mean rate previously reported for Europe (based on seven countries including Austria) $[15,16]$, across all patient groups (85 versus 91 in T1DM and $15-28$ versus $20-35$ in T2DM) $[15,16]$. The proportion of events which occur at night-time in Austria (19\% in T1DM and $15-22 \%$ in T2DM) is also comparable to the results across all European countries studied ( $22 \%$ in T1DM and 22-32\% in T2DM) [15].

In Austria, the self-reported NSHE rate in T1DM respondents is four times greater than the rates reported by T2DM respondents. It has previously been shown that the risk of hypoglycaemia in people with insulin-treated
T2DM increases with increasing diabetes duration [8], and Henderson et al. [22] reported that NSHE frequency among people with T2DM only reaches the same level as in people with T1DM after 10 years of insulin use in T2DM [22]. In the present study, only $39 \%$ of respondents with T2DM had received insulin for over 10 years (compared to $70 \%$ of respondents with T1DM), which may help to explain the lower frequency of NSHEs. In T2DM the frequency of NSHE also varies according to treatment regimen, although this is expected due to the different types of insulin coverage [23].

Although we report a mean annual NSHE rate of 85 in T1DM and 22 in T2DM patients in Austria, sub-analyses suggest that some patients are more susceptible to hypoglycaemia. Over a third $(37 \%)$ of all respondents did not experience any NSHEs during the four week study period; a sub-analysis excluding these respondents increases the mean annual NSHE rate by $18 \%$ in respondents with T1DM, and by $77 \%$ in respondents with T2DM (ranging from a $54 \%$ increase in T2BOT to $140 \%$ in T2BOT respondents). Looking specifically at nocturnal events, although the mean annual rate was 16 in T1DM and 5 in T2DM respondents, $50 \%$ of respondents with T1DM and $78 \%$ of T2DM respondents did not experience any nocturnal NSHEs during the study. A sub-analysis of the respondents who reported at least one nocturnal event resulted in nearly double the nocturnal NSHE rate in T1DM and increased it 4-fold in T2DM respondents. These results suggest an increased risk of hypoglycaemia in patients with a history of events, a finding which has been reported previously [24-30]. As some patients may not regularly experience NSHEs (one third of this study population), or only experience them during the daytime (two thirds of this study population), the real world burden in those that have regular hypoglycaemic events may be higher than previously reported. It is important to consider that the current results only relate to a fourweek period, so further research is warranted to better understand this issue.

In the present study, we investigated patients' selfreported ability to recognise the symptoms of hypoglycaemia. There is no consensus on how to classify awareness, however our method benefits from the use of three categories (instead of two-aware/unaware-as in the Clarke [31] and Gold [32] methods), which enables identification of the gradual loss of awareness. In addition, it is the only method proven to perform similarly across language barriers [33]. The proportion of respondents in Austria reportedly 'aware' of hypoglycaemic symptoms was higher than the average across Northern and Central Europe in both T1DM (48\% versus $36 \%$ ) and T2DM respondents (43-61\% versus 36-51\%) [15]. Despite higher awareness levels in Austria compared to the rest of Northern and Central Europe, a substantial proportion of our study population ( $47 \%$ ) had impaired awareness or unawareness. Impaired awareness has been linked to reduced adherence to recommended changes in insulin regimen [34], and has been reported as the most important risk factor for severe hypoglycaemia [35]. 
A number of previous studies have shown a statistically significant $(p<0.05)$ increase in SHEs in patients with reduced awareness [34, 36-39]. In line with this, our study showed a trend (although not statistically significant) for increased SHE and NSHE rates with reduced levels of awareness (in respondents with T1DM). In the overall European study, these trends were statistically significant $(p<0.05)$ [16]. This could be explained by unaware respondents not taking preventative action to stop the onset of hypoglycaemia, because they are unable to recognise the symptoms of low blood sugar. Additionally, this inability may cause respondents to overcompensate by testing their blood glucose more frequently, resulting in the identification of more events.

We also found that a high proportion of respondents in Austria were reluctant to discuss their hypoglycaemia with their GP/specialist ( $67 \%$ of T1DM and $49 \%$ of T2DM; comparable to the mean percentages across Northern and Central Europe) [15]. This may be due to wider factors such as a fear of losing driving privileges [11], impacts in the work environment, or concerns that their GP may think they have poor control of their diabetes.

Unsurprisingly, NSHE were associated with reduced physical and emotional well-being, regardless of the time of day the NSHE occurred. The negative emotional impact of NSHEs was comparable across diabetes types; tiredness/fatigue and reduced alertness were the most commonly reported effects in both T1DM and T2DM respondents. This supports a previous study in which patients reported that hypoglycaemia affects their daily life and causes anxiety [10]. The health-related impact of hypoglycaemia has been further confirmed using the EQ-5D and SF-36; a study of diabetes patients in the UK reported that as the frequency and severity of hypoglycaemia increased, quality of life and health-related utility decreased [7].

In our study, patients increased their self-monitoring of glucose levels in response to a NSHE. Whilst this is an appropriate adaptive behaviour which may help prevent new events in the short-term [11], it increases healthcare resource use (i.e. increase in BGM test-strip consumption) and is therefore associated with a cost burden. This burden could be alleviated if NSHE frequency was reduced, through improved awareness and recognition of events. An additional contributor to the direct cost burden of NSHEs in Austria is patient contact with physicians to report their event. NSHE also present an indirect cost burden in Austria through lost work time. This is reported in further detail by Geelhoed-Duijvestijn et al. [16].

Limitations of this study should be considered and have been discussed previously by Östenson et al. [15] and Geelhoed-Duijvestijn et al. [16]. Respondent demographics show that $6 \%$ of Austrian respondents with T1DM were receiving basal-only insulin, however this formulation should only be used in patients with T2DM, and therefore we presume that most of these respondents incorrectly reported their diabetes type as T1DM.
Given that T2DM is associated with fewer hypoglycaemic events, our study may underestimate the true frequency of events among respondents with T1DM.

Secondly, the survey relies on respondents ability to recall their NSHEs frequency over the preceding 7-day period, which might have introduced a bias related to the interpretation of symptoms. However, a previous study reported that a respondent's recall of NSHEs during the previous week was not significantly different from the prospective recording of events over the same time period [14]. The recruitment method, which required having an email address and used online panels to locate patients, could have introduced selection bias. However, the internet penetration rate in Austria is higher than the average across Europe, based on data from 2012 (80\% in Austria compared to $73 \%$ across the European Union and $64 \%$ across Europe) [40] and recruitment was done via broad panels reflective of the general population. As respondents were not informed that the survey was about hypoglycaemia prior to enrolling, there is no reason to suggest any selection bias towards people struggling with hypoglycaemia in the first wave of the study. However since the response rates for waves of the study diminished (82, 72 and $67 \%$ of respondents completed wave two, three and four respectively), we cannot rule out the possibility that later waves were completed by respondents who had more experience of hypoglycaemic events.

Despite these limitations, this study provides important real-world rates of hypoglycaemia in Austria, both during the day and at night-time, addressing the lack of data available for this population. Many patients are unable to recognise the symptoms of a hypoglycaemic event, and also express a reluctance to discuss their hypoglycaemia with physicians. The importance of improving glycaemic control is evidenced by the negative impact on healthcare resource use and work productivity in Austria that results from even non-severe events.

\section{Acknowledgements}

The authors would like to acknowledge The Hypoglycaemia in Insulin Treated Patients (HIT) Study Group (with representatives from 11 European countries) for their involvement in the overall study, and Adelphi Values for their editorial support in the preparation of this manuscript.

\section{Compliance with ethics}

This was a non-interventional market research study. Questionnaires were completed anonymously in accordance to the regulations and practice of market research governing bodies: European Society for Opinion and Marketing Research (ESOMAR) and European Pharmaceutical Market Research Association (EphMRA). The EphMRA Code of Conduct states that Market Research does not require Clinical Research Ethics Committee or Independent Review Board approval. Informed consent was obtained from all patients for being included in the study. 


\section{Conflict of interest}

RW has received honoraria for lectures and as a member of the Advisory Board for Novo Nordisk, Eli Lilly, Sanofi, Novartis, Medtronic, MSD, Takeda, Astra Zeneca/ BMS, Boehringer-Ingelheim, Janssen-Cilag, Nintamed and Roche Diagnostics. SL is employed by Novo Nordisk Scandinavia AB.

\section{Open Access}

This article is distributed under the terms of the Creative Commons Attribution License which permits any use, distribution, and reproduction in any medium, provided the original author(s) and the source are credited.

\section{References}

1. International Diabetes Federation. 2013. IDF Diabetes Atlas, 6th edn. Brussels, Belgium: International Diabetes Federation. Available at: http://www.idf.org/diabetesatlas. Accessed 13 February 2014.

2. Österreichischer D. 2013. www.bmg.gv.at/Publikationen. Accessed 31 March 2014.

3. Lechleitner M, Roden M, Weitgasser R, Ludvik B, Fasching P, Hoppichler F, et al. Insulintherapie bei diabetes mellitus. Wien Klin Wochenschr. 2012;124:17-22.

4. UK Hypoglycaemia Study Group. Risk of hypoglycaemia in types 1 and 2 diabetes: effects of treatment modalities and their duration. Diabetologia. 2007;50:1140-7.

5. ADA Workgroup on Hypoglycemia. Defining and Reporting Hypoglycemia in Diabetes. Diabetes Care. 2005;28(5):1245-9.

6. CHMP. Guidelines on clinical investigation of medical products in the treatment or prevention of diabetes mellitus. 2012. http://www.ema.europa.eu/ema/index. jsp?curl=pages/includes/document/document_detail.jsp ?webContentId=WC500129256\& $\mathrm{mid}=$ WC0b01 ac058009a 3dc. Accessed July 2013. European Medicines Agency.

7. Davis RE, Morrissey M, Peters JR, Wittrup-Jensen K, Kennedy-Martin T, Currie CJ. Impact of hypoglycaemia on quality of life and productivity in type 1 and type 2 diabetes. Curr Med Res Opin. 2005;21(9):1477-83.

8. Donnelly LA, Morris AD, Frier BM, Ellis JD, Donnan PT, Durrant R, et al. Frequency and predictors of hypoglycaemia in Type 1 and insulin-treated Type 2 diabetes: a population-based study. Diabet Med. 2005;22(6):749-55.

9. Brod M, Christensen T, Thomsen TL, Bushnell DM. The impact of non-severe hypoglycemic events on work productivity and diabetes management. Value Health. 2011;14(5):665-71.

10. Lundkvist J, Berne C, Bolinder B, Jonsson L. The economic and quality of life impact of hypoglycemia. Eur J Health Econ. 2005;6(3):197-202.

11. Wild D, von MR, Brohan E, Christensen T, Clauson $\mathrm{P}$, Gonder-Frederick L. A critical review of the literature on fear of hypoglycemia in diabetes: Implications for diabetes management and patient education. Patient Educ Couns. 2007;68(1):10-5.

12. Leiter LA, Yale JF, Chiasson JL, Harris S, Kleinstiver P, Sauriol L. Assessment of the Impact of Fear of Hypoglycemic Episodes on Glycemic and Hypoglycemia Management. Canadian. J Diabetes. 2005;29(3):1-7.

13. Zivilisationskrankheit D: Ausprägungen - Lösungsansätze - Herausforderungen. Bundesministerium für Gesundheit, 2013; ISBN: 978-3-85159-181-1.
14. Pramming S, Thorsteinsson B, Bendtson I, Binder C. Symptomatic hypoglycaemia in 411 type 1 diabetic patients. Diabet Med. 1991;8(3):217-22.

15. Östenson CG, Geelhoed-Duijvestijn P, Lahtela J, Weitgasser R, Markert Jensen M, Pedersen-Bjergaard U. Self-reported non-severe hypoglycaemic events in Europe. Diabet Med. 2014;31(1):92-101.

16. Geelhoed-Duijvestijn PH, Pedersen-Bjergaard U, Weitgasser R, Lahtela J, Jensen MM, Ostenson CG. Effects of patient-reported non-severe hypoglycemia on healthcare resource use, work-time loss, and wellbeing in insulintreated patients with diabetes in seven European countries. J Med Econ. 2013;16(12):1453-61.

17. ESOMAR. ICC/ESOMAR International Code on Market and Social Research. 2007. http://www.esomar.org/uploads/ public/knowledge-and-standards/codes-and-guidelines/ ICCESOMAR_Code_English_.pdf. Accessed July 2013. International Chamber of Commerce (ICC).

18. EphMRA. 1997. Code of Conduct http://www.ephmra. org/professional-standards/mr-code-of-conduct.aspx. Accessed July 2013.

19. Pedersen-Bjergaard U, Pramming S, Thorsteinsson B. Recall of severe hypoglycaemia and self-estimated state of awareness in type 1 diabetes. Diabetes Metab Res Rev. 2003;19(3):232-40.

20. Pedersen-Bjergaard U, Pramming S, Heller SR, Wallace TM, Rasmussen AK, Jorgensen HV, et al. Severe hypoglycemia in 1076 adult patients with type 1 diabetes: influence of risk markers and selection. Diabetes Metab Res Rev. 2004;20(6):479-86.

21. Kristensen PL, Hansen LS, Jespersen MJ, Pedersen-Bjergaard U, Beck-Nielsen H, Christiansen JS, et al. Insulin analogues and severe hypoglycaemia in type 1 diabetes. Diabetes Res Clin Pract. 2012;96(1):17-23.

22. Henderson JN, Allen KV, Deary IJ, Frier BM. Hypoglycaemia in insulin-treated Type 2 diabetes: frequency, symptoms and impaired awareness. Diabet Med. 2003;20(12):1016-21.

23. Inzucchi SE, Bergenstal RM, Buse JB, Diamant M, Ferrannini E, Nauck M, et al. Management of hyperglycaemia in type 2 diabetes: a patient-centred approach. Position statement of the American Diabetes Association (ADA) and the European Association for the Study of Diabetes (EASD). Diabetologia. 2012;55(6):1577-96.

24. DCCT Research Group. Hypoglycemia in the Diabetes Control and Complications Trial. Diabetes. 1997;46(2):271-86.

25. Arbelaez AM, Cryer PE. Hypoglycemia in diabetes: prevalence, mechanisms, impact and prevention. International Diabetes Monitor. 2009;21(6):206-9.

26. Miller CD, Phillips LS, Ziemer DC, Gallina DL, Cook CB, ElKebbi IM. Hypoglycemia in patients with type 2 diabetes mellitus. Arch Intern Med. 2001;161(13):1653-9.

27. Davis TM, Brown SG, Jacobs IG, Bulsara M, Bruce DG, Davis WA. Determinants of severe hypoglycemia complicating type 2 diabetes: the Fremantle diabetes study. J Clin Endocrinol Metab. 2010;95(5):2240-7.

28. Donnelly LA, Morris AD, Frier BM, Ellis JD, Donnan PT, Durrant R, et al. Frequency and predictors of hypoglycaemia in Type 1 and insulin-treated Type 2 diabetes: a population-based study. Diabet Med. 2005;22(6):749-55.

29. Cryer PE, Davis SN, Shamoon H. Hypoglycemia in diabetes. Diabetes Care. 2003;26(6):1902-12.

30. Cariou B, Lievre M, Huet D, Charbonnel B, Sert C, Gouet D Hypoglycaemia among 3048 insulin-treated patients in real life: frequency and predictive factors: results from the prospective DIALOG study. European Association for the Study of Diabetes (EASD) 49th annual meeting 2013 (abstract \#591). 
31. Clarke WL, Cox DJ, Gonder-Frederick LA, Julian D, Schlundt D, Polonsky W. Reduced awareness of hypoglycemia in adults with IDDM. A prospective study of hypoglycemic frequency and associated symptoms. Diabetes Care. 1995;18(4):517-22.

32. Gold AE, MacLeod KM, Frier BM. Frequency of severe hypoglycemia in patients with type I diabetes with impaired awareness of hypoglycemia. Diabetes Care. 1994;17(7):697-703.

33. Hoi-Hansen T, Pedersen-Bjergaard U, Thorsteinsson B. Classification of hypoglycemia awareness in people with type 1 diabetes in clinical practice. J Diabetes Complications. 2010;24(6):392-7.

34. Smith CB, Choudhary P, Pernet A, Hopkins D, Amiel SA. Hypoglycemia unawareness is associated with reduced adherence to therapeutic decisions in patients with type 1 diabetes: evidence from a clinical audit. Diabetes Care. 2009;32(7):1196-8.

35. Akram K, Pedersen-Bjergaard U, Carstensen B, BorchJohnsen K, Thorsteinsson B. Frequency and risk factors of severe hypoglycaemia in insulin-treated Type 2 diabetes: a cross-sectional survey. Diabet Med. 2006;23(7):750-6.
36. Gold AE, MacLeod KM, Frier BM. Frequency of severe hypoglycemia in patients with type I diabetes with impaired awareness of hypoglycemia. Diabetes Care. 1994;17(7):697-703.

37. Geddes J, Schopman JE, Zammitt NN, Frier BM. Prevalence of impaired awareness of hypoglycaemia in adults with Type 1 diabetes. Diabet Med. 2008;25(4):501-4.

38. Choudhary P, Geddes J, Freeman JV, Emery CJ, Heller SR, Frier BM. Frequency of biochemical hypoglycaemia in adults with Type 1 diabetes with and without impaired awareness of hypoglycaemia: no identifiable differences using continuous glucose monitoring. Diabet Med. 2010;27(6):666-72.

39. Schopman JE, Geddes J, Frier BM. Frequency of symptomatic and asymptomatic hypoglycaemia in Type 1 diabetes: effect of impaired awareness of hypoglycaemia. Diabet Med. 2011;28(3):352-5.

40. Internet World Stats. 2012. Internet Penetration Rates http://www.internetworldstats.com/europa2.htm. Accessed July 2013. Usage and population statistics. 